\title{
Electron-Beam Patterning of Vapor-Deposited Solid Anisole
}

\author{
Zhao, Ding; Chang, Bingdong; Beleggia, Marco
}

\section{Published in:}

ACS Applied Materials and Interfaces

Link to article, DOI:

10.1021/acsami.9b19778

Publication date:

2020

Document Version

Peer reviewed version

Link back to DTU Orbit

Citation (APA):

Zhao, D., Chang, B., \& Beleggia, M. (2020). Electron-Beam Patterning of Vapor-Deposited Solid Anisole. ACS Applied Materials and Interfaces, 12(5), 6436-6441. https://doi.org/10.1021/acsami.9b19778

\section{General rights}

Copyright and moral rights for the publications made accessible in the public portal are retained by the authors and/or other copyright owners and it is a condition of accessing publications that users recognise and abide by the legal requirements associated with these rights.

- Users may download and print one copy of any publication from the public portal for the purpose of private study or research.

- You may not further distribute the material or use it for any profit-making activity or commercial gain

- You may freely distribute the URL identifying the publication in the public portal

If you believe that this document breaches copyright please contact us providing details, and we will remove access to the work immediately and investigate your claim. 
ACS APPLIED MATERTNLS
QINTER CESS

Applications of Polymer, Composite, and Coating Materials

Electron-beam patterning of vapor-deposited solid anisole

Ding Zhao, Bingdong Chang, and Marco Beleggia

ACS Appl. Mater. Interfaces, Just Accepted Manuscript • DOI: 10.1021/acsami.9b19778 • Publication Date (Web): 16 Jan 2020

Downloaded from pubs.acs.org on January 20, 2020

\section{Just Accepted}

"Just Accepted" manuscripts have been peer-reviewed and accepted for publication. They are posted online prior to technical editing, formatting for publication and author proofing. The American Chemical Society provides "Just Accepted" as a service to the research community to expedite the dissemination of scientific material as soon as possible after acceptance. "Just Accepted" manuscripts appear in full in PDF format accompanied by an HTML abstract. "Just Accepted" manuscripts have been fully peer reviewed, but should not be considered the official version of record. They are citable by the Digital Object Identifier (DOI®). "Just Accepted" is an optional service offered to authors. Therefore, the "Just Accepted" Web site may not include all articles that will be published in the journal. After a manuscript is technically edited and formatted, it will be removed from the "Just Accepted" Web site and published as an ASAP article. Note that technical editing may introduce minor changes to the manuscript text and/or graphics which could affect content, and all legal disclaimers and ethical guidelines that apply to the journal pertain. ACS cannot be held responsible for errors or consequences arising from the use of information contained in these "Just Accepted" manuscripts. 


\title{
Electron-beam patterning of vapor-deposited solid anisole
}

\author{
Ding Zhao*, Bingdong Chang, and Marco Beleggia* \\ DTU Nanolab, National Centre for Nano Fabrication and Characterization, Technical University \\ of Denmark, Kongens Lyngby 2800, Denmark
}

KEYWORDS: Electron-beam patterning; Electron-beam lithography; Ice lithography; Solid anisole; Cryogenic temperature; 3D nanofabrication

\begin{abstract}
The emerging ice lithography (IL) nanofabrication technology differs from conventional electron-beam lithography (EBL) by working at cryogenic temperatures and using vapor-deposited organic molecules, such as solid water and alkanes, as e-beam resists. In this paper, we investigate systematically e-beam patterning of frozen anisole and assess its performance as an e-beam resist in IL. Dose curves reveal that anisole has a very low contrast of $\sim 1$, with a very weak dependence on primary beam energy in the investigated range of 5-20 keV. The minimum line width of $60 \mathrm{~nm}$ is attainable at $20 \mathrm{keV}$, limited by stage vibration in our apparatus. Notably, various solid states of anisole have been observed and we can control the deposited anisole from crystalline to amorphous state by decreasing the deposition temperature. The critical temperature for forming an amorphous film is $130 \mathrm{~K}$ in the vacuum of the microscope chamber. Smooth patterns with surface roughness of $\sim 0.7 \mathrm{~nm}$ are achieved in asdeposited amorphous solid anisole. As a proof of principle of 3D fabrication, we finally fabricate nanoscale patterns on exotic silicon micropillars with high aspect ratio using this resist.
\end{abstract}




\section{INTRODUCTION}

The flexible nanoscale positioning and writing afforded by scanning electron microscopy has prompted the development of a variety of electron-beam-based patterning methods. ${ }^{1-12}$ The most striking example is electron-beam lithography (EBL), which has been widely implemented for patterning micro/nano-structures with advantages of high resolution and reliability. ${ }^{13-20}$ In EBL, an electron-sensitive resist is spin- or spray-coated on a flat substrate, then exposed by a focused e-beam and developed in a solvent for the creation of nanoscale patterns. These patterns subsequently act as stencils, which will be filled with required materials by deposition or transferred into the underlying material by etching.

Traditional EBL nanofabrication is limited to patterning on planar substrates and often involves various chemicals in lithographic steps. To extend EBL processing to irregular surfaces (e.g. curved surfaces or structured substrates), efforts have been devoted on alternative methods for coating resists, such as thermal evaporation coating, ${ }^{21,22}$ spin coating using low viscosity resists, ${ }^{23,24}$ and float coating. ${ }^{25}$ For instance, the polystyrene (PS) resist can be applied by thermal evaporation, which allows EBL on an atomic force microscope (AFM) cantilever or optical fibers. ${ }^{21,22}$ Another strategy is to transfer the EBL resist with nanopatterns prepared on a planar substrate to other receiver substrates. For example, a suspended poly (methyl methacrylate) (PMMA) mask can be obtained after detaching from its original substrate in a solvent, and then transferred to the surface of fibers or convex lens. ${ }^{26}$ Like other traditional EBL resists, both PS and PMMA need elaborate procedures for further processing, especially during chemical development. Recently, natural materials, such as silk $^{27}$ and egg white ${ }^{28}$, have been demonstrated as EBL resists that can be developed in water. Although this new kind of resists enables a green 
process flow, the restriction that EBL fabrication is limited to flat substrates still exists, since spin-coating is adopted to form the silk or egg white film.

Ice lithography (IL) is an emerging e-beam-based lithography technique..$^{29,30}$ The process is ecofriendly and streamlined, starting with vapor-deposited ice on a cryo-cooled sample and ending with removal of the unexposed ice by heating up the sample. Compared to traditional EBL, significant advantages have been achieved in IL using ice resists that allow effective coating on 3D objects and simple development without liquid chemicals, leading to nanofabrication on delicate and fragile substrates. ${ }^{31}$ Currently, the research on IL is still in its infancy, and only a few condensed materials have been explored, such as water ice as a positive-tone resist ${ }^{32,33}$ and solid alkanes as negative-tone resists. ${ }^{34,35}$ Anisole condensed at cryogenic temperature also demonstrated resist-like capabilities, which can be used to fabricate line patterns and multilayered structures ${ }^{34}$. However, how to control the state of solid anisole and its performance for IL applications have not been studied systematically. In this work, we investigate the contrast, sensitivity and resolution of frozen anisole as an e-beam resist at various primary beam energies. Other lithographic properties including dense-line patterns, temperature- and timedependent patterning are also studied. As a proof of principle of 3D fabrication, we fabricate nanoscale patterns on exotic silicon micropillars with high aspect ratio using this resist.

\section{Experimental details}

Anisole was purchased from MicroChem and used without further purification. It usually acts as a thinner to dilute PMMA resists. Pristine silicon wafers (with few nanometers of native oxide) served as substrates for condensing anisole vapor. Aluminum alignment marks with thickness of 
$300 \mathrm{~nm}$ were prepared on silicon by UV lithography. The wafers were then cleaved into $10 \mathrm{~mm}$ by $10 \mathrm{~mm}$ pieces for further processing.

The IL instrumentation and its operation have been described in detail previously. ${ }^{36}$ In brief, this apparatus consists of an EBL system, a gas injection system (GIS), a cryostage cooled by liquid nitrogen and a load-lock pumped by a turbo pump in series with a dry backing pump. The EBL system is based on LEO (Zeiss) 1550 which is a high-performance scanning electron microscope (SEM) with a thermal field-emission filament, and a Raith Elphy Quantum pattern generator was equipped to define the written pattern structures. The typical pressure of SEM chamber is $2 \times 10^{-6}$ mbar during cooling sample. Liquid anisole is stored in a glass vial and anisole molecules are introduced into the SEM chamber for deposition by a fine leak valve in GIS. The relative deposition rate is monitored by a Pirani gauge. The cryostage temperature is controlled independently with an internal heater.

Samples were cooled down to $130 \mathrm{~K}$ and amorphous solid anisole was vapor deposited onto cold silicon substrates (see Fig. 1a). After e-beam exposure, the samples were moved into the loadlock and warmed up to room temperature. During this thermal development, unexposed solid anisole sublimated in vacuum. The samples were then removed from the vacuum for further evaluation.

Preliminary characterization of pattern qualities was performed with a Nikon Eclipse L200N optical microscope under bright field illumination. Fine-line patterns and pattern drift were measured by a Zeiss Supra 60 VP SEM. Thickness and roughness measurements were performed by a Bruker Dimension Icon AFM in peak force tapping mode. Since it is difficult to measure the 
initial property of as-deposited solid anisole in situ, the thickness and roughness mentioned below refers to those characterized on exposed resist patterns.

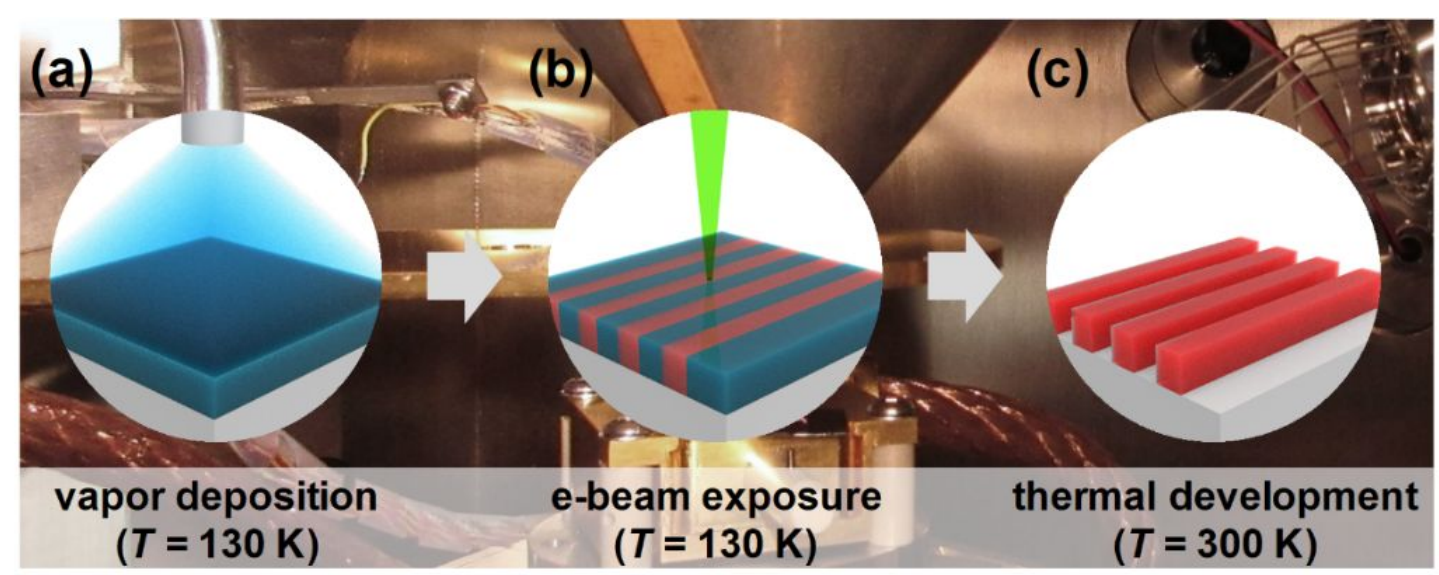

Figure 1. Process flow in the IL instrument. (a) Vapor-deposited amorphous solid anisole on silicon at $130 \mathrm{~K}$. (b) A focused e-beam exposed solid anisole for patterning. (c) Unexposed solid anisole sublimated in vacuum and designed patterns remained on substrate. The background image shows interior view of our modified SEM.

\section{RESULTS AND DISCUSSION}

\subsection{Contrast and sensitivity of solid anisole}

An amorphous solid anisole film was prepared as described above. Arrays of $4 \times 4 \mu \mathrm{m}^{2}$ squares spaced $4 \mu \mathrm{m}$ apart were patterned in a single write field $\left(550 \times 550 \mu \mathrm{m}^{2}\right)$ with accelerating voltages of 5, 10, and $20 \mathrm{kV}$, respectively. Optical microscopic images (see Figs. 2a-c) were used to identify the approximate onset dose and saturation dose for solid anisole resist (by observing when patterned material emerged and when color of patterns no longer changed). The squares patterned with doses below the saturation dose allow the calculations of contrast and sensitivity by measuring the thickness of partially exposed patterns. The red shift of structural color 
indicated an increasing pattern thickness when a higher exposure dose is applied. For $20 \mathrm{keV}$, the patterned squares at high doses are slightly broadened (see first row in Fig. 2c) owing to proximity effect.

The contrast and sensitivity are important quality characteristics for e-beam resists. Generally, a resist with high contrast enables close packing of patterned features, while with low contrast allows flexible thickness control of partially exposed resists, which is beneficial for gray-scale lithography. ${ }^{37}$ For a resist with higher sensitivity, less amount of incident electrons are required for the exposure process, resulting in a higher writing speed and thus a larger throughput. Here, the fully exposed squares are $209 \mathrm{~nm}$ thick at $5 \mathrm{keV}$ and $10 \mathrm{keV}$ and we take it as a baseline for contrast and sensitivity calculations. At $20 \mathrm{keV}$, those squares get a little thicker, probably due to bubbles caused by gas release in the resist film. A trend line is drawn between the points lie at normalized thickness of $20 \%$ and $80 \%$, and its slope is used to calculate the contrast $\gamma$, defined as $\gamma=0.6 /\left[\log _{10}\left(D_{80}\right)-\log _{10}\left(D_{20}\right)\right] \cdot{ }^{38} \mathrm{We}$ can also obtain $D_{\mathrm{O}}$ and $D_{\mathrm{S}}$ by extrapolating the line to 0 and $100 \%$, that is intercepting the dose-axis at $D_{\mathrm{O}}$ and providing a normalized thickness value of 1 at $D_{\mathrm{S}} . D_{\mathrm{S}}$ represents the sensitivity of a resist. For varying primary beam energies, the contrast values are nearly one (1.02 at $5 \mathrm{keV}, 1.08$ at $10 \mathrm{keV}$ and $20 \mathrm{keV})$, indicating that solid anisole has a very low contrast comparable to the standard SU-8 e-beam resist (0.7-1.7) ${ }^{39}$ Consistent with reports for traditional EBL resists and nonane ice, the $D_{\mathrm{S}}$ of solid anisole decreases when reducing the beam energy, as shown in Fig. 2d, implying the resist is more sensitive to electrons with lower energies. Sensitivity also reflects process time for a resist. At $20 \mathrm{keV}$, the time required for full exposure of solid anisole resist is almost 4 times that of $5 \mathrm{keV}$. 
(a) $5 \mathrm{keV}$

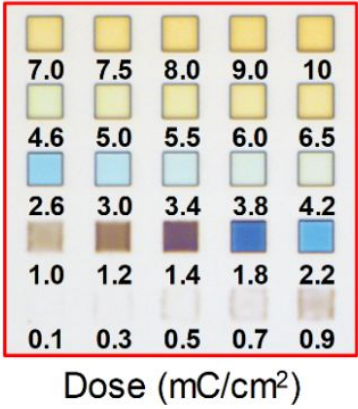

(b) $10 \mathrm{keV}$

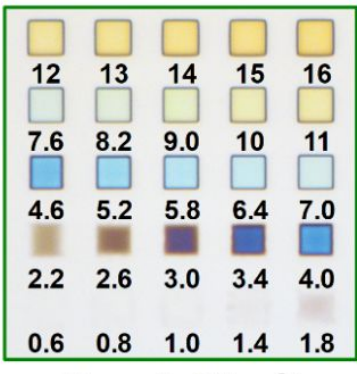

Dose $\left(\mathrm{mC} / \mathrm{cm}^{2}\right)$ (c) $20 \mathrm{keV}$

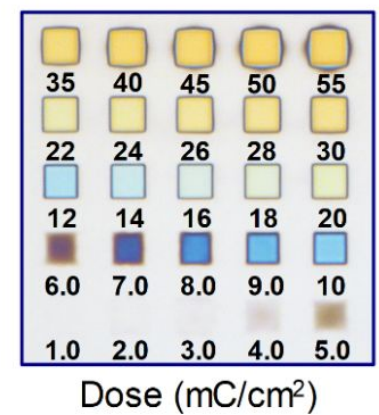

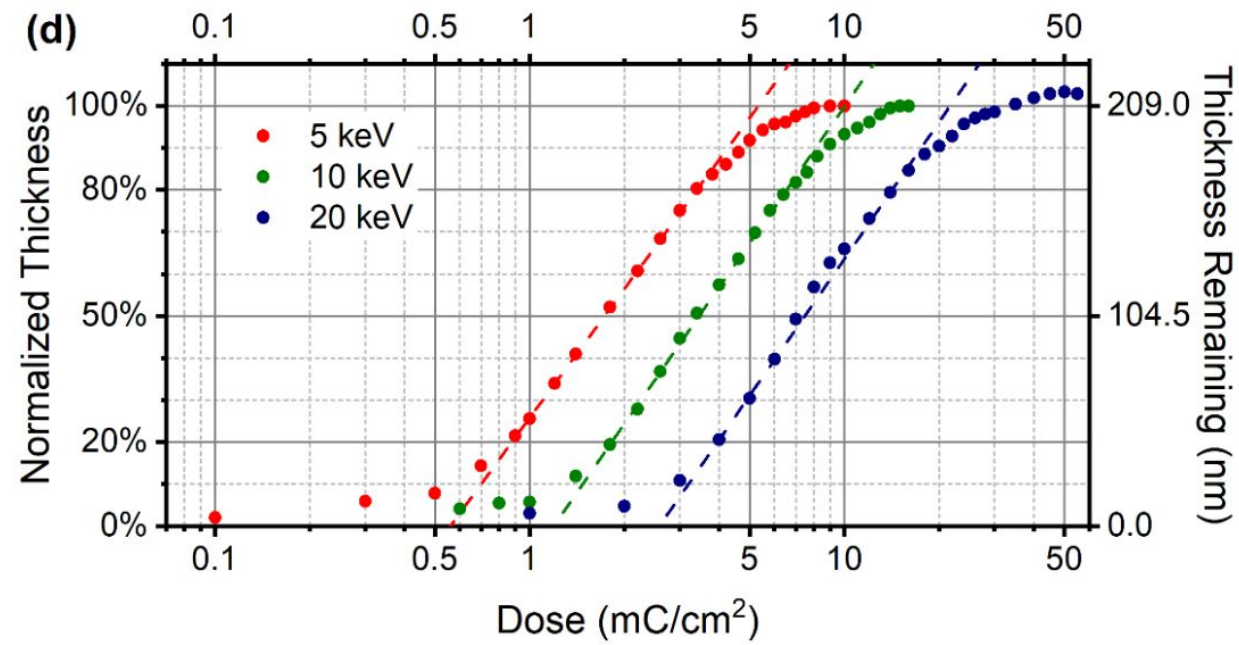

Figure 2. (a-c) Optical microscopic images of patterned square arrays on silicon. Each $4 \times 4 \mu^{2}$ square represents a different e-beam dose as stated below, increasing from bottom left to top right. The square got thick with increasing dose resulting in a red shift of its color. (d) Dose curves for varying primary beam energies in solid anisole resist. The resist thickness after ebeam exposure was measured by AFM.

\subsection{Line patterning with solid anisole}

To test the resolution of solid anisole at large accelerating voltages, line patterns were created with varying doses and pitches. Amorphous solid anisole was prepared under the same conditions as in the contrast and sensitivity study, except with a thinner (50 nm) layer, and line 
doses $(\mu \mathrm{C} / \mathrm{cm})$ were employed for patterning, instead of area doses $\left(\mathrm{mC} / \mathrm{cm}^{2}\right)$. Figure 3a presents patterned single pixel lines with tens of micron length and doses increased from $0.1 \mu \mathrm{C} / \mathrm{cm}$ (bottom) to $1.0 \mu \mathrm{C} / \mathrm{cm}$ (up) at $20 \mathrm{keV}$. Lines were spaced $1 \mu \mathrm{m}$ apart to reduce proximity effect. As shown in magnified SEM images, the patterned line was barely visible at $0.1 \mu \mathrm{C} / \mathrm{cm}$ and a dot-line appeared at $0.2 \mu \mathrm{C} / \mathrm{cm}$. We noted connections between isolated dots in the patterned line with a dose of $0.3 \mu \mathrm{C} / \mathrm{cm}$, and continuous lines were obtained with doses above $0.4 \mu \mathrm{C} / \mathrm{cm}$, indicating the critical line dose should be between $0.3 \mu \mathrm{C} / \mathrm{cm}$ and $0.4 \mu \mathrm{C} / \mathrm{cm}$.

Furthermore, we patterned lines spaced from $100 \mathrm{~nm}$ to $600 \mathrm{~nm}$ with dose of $0.35 \mu \mathrm{C} / \mathrm{cm}$ in Fig. 3b. Two adjacent lines started to merge when the space was $100 \mathrm{~nm}$, while they were clearly distinguished if the space was $200 \mathrm{~nm}$ or more. High-resolution lines were finally produced with line widths of $61 \mathrm{~nm}$ in Fig. 2c, consistent with previously reported in anisole ice. ${ }^{34}$ The lines were spaced $155 \mathrm{~nm}$ apart, and the middle one was extended to check that close packing has little effect on the minimum resolution. It is worth noting that stage vibration exists in most of SEM systems, which often leads to fluctuated edges of nanostructures in high magnification images. This has been the main limitation on lithography resolution in our instrument. ${ }^{36}$ 


\section{(a)}

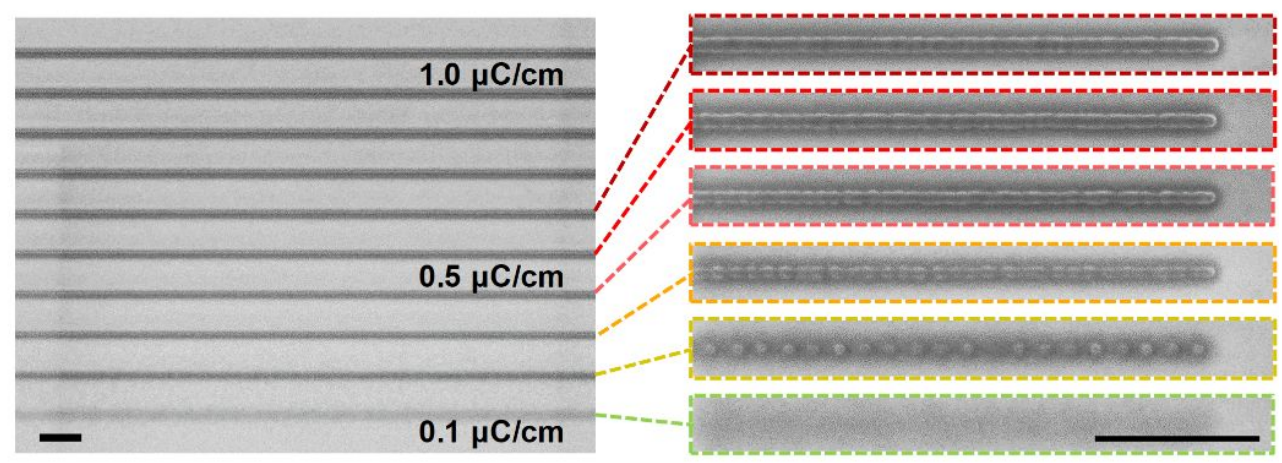

(b)

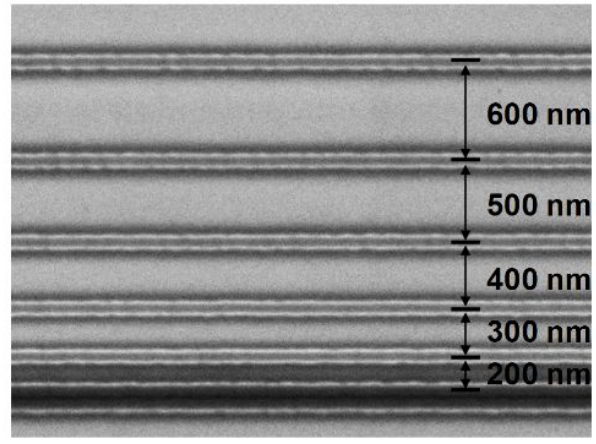

(c)

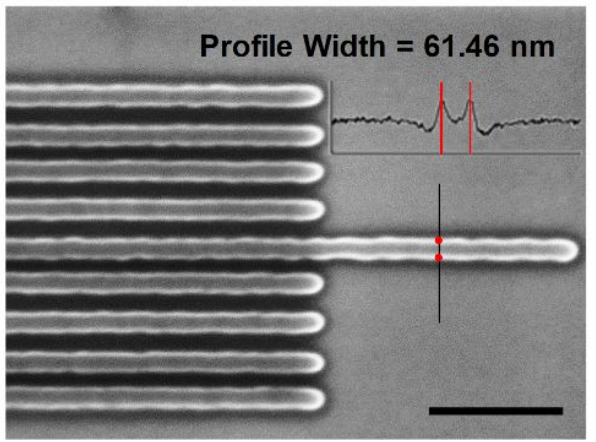

Figure 3. (a) SEM images of single pixel lines defined by a $20 \mathrm{keV}$ e-beam in a $50 \mathrm{~nm}$ thick solid anisole resist on silicon. The e-beam patterning dose increased evenly from $0.1 \mu \mathrm{C} / \mathrm{cm}$ (bottom, line barely visible) to $1.0 \mu \mathrm{C} / \mathrm{cm}$ (up). Magnified images show patterned lines become continuous for dose above $0.4 \mu \mathrm{C} / \mathrm{cm}$. Scale bars are $1 \mu \mathrm{m}$. (b) SEM image of patterned lines spaced from $100 \mathrm{~nm}$ (bottom, lines overlapped) to $600 \mathrm{~nm}$ (up). The patterning dose is 0.35 $\mu \mathrm{C} / \mathrm{cm}$. (c) SEM image of dense lines with a pitch of $155 \mathrm{~nm}$. The line width was measured by SEM image contrast. The middle line was extended to check that close packing of lines has little effect on the minimum resolution. Scale bar is $500 \mathrm{~nm}$.

\subsection{Temperature- and time-dependent patterning}

In ice lithography, vapor deposition of solid resist is the first and an essential step, during which different types of ice can form under various conditions. A common example is water ice, the eighteenth solid phase of which has just been discovered. ${ }^{40}$ However, a uniform amorphous form 
of the ice resist is usually preferred for lithography, because crystalline structures may affect propagation of electrons and thus induce pattern distortions. In practice, a larger roughness is observed on pattern surfaces when using negative-tone crystalline ice resists.

By decreasing the deposition temperature, we were able to manipulate vapor-deposited solid anisole from crystalline to amorphous form. In situ cryogenic SEM images were used to monitor the change of surface morphology on solid anisole in vacuum (see Fig. 4). We kept the same pressure drops in GIS to ensure a similar amount of anisole molecules introduced for each deposition. At a high deposition temperature, i.e. $150 \mathrm{~K}$, a granular solid anisole film was formed and the root-mean-square (RMS) surface roughness inside a $4 \times 4 \mu \mathrm{m}^{2}$ square region was measured as $10.4 \mathrm{~nm}$. A striated solid anisole with smaller grains appeared at $140 \mathrm{~K}$, with a reduced surface roughness of $9.51 \mathrm{~nm}$. When lowering cryostage temperature to $135 \mathrm{~K}$, we deposited a solid anisole film containing both crystalline and amorphous features, indicating that we were approaching the critical temperature for formation of amorphous anisole. As shown in Fig. 4c, the amorphous anisole surface had a RMS roughness of $1.27 \mathrm{~nm}$, which was much smoother than the crystalline as expected. Finally, a flat anisole film with thickness of $107 \mathrm{~nm}$ and roughness less than $1 \mathrm{~nm}$ was achieved (Fig. 4d), implying the temperature for amorphous formation was $130 \mathrm{~K}$ or below. Moreover, after slowly annealing this film from $130 \mathrm{~K}$ to $160 \mathrm{~K}$ (about 50 minutes), we developed another form of solid anisole with an island nanostructure. 

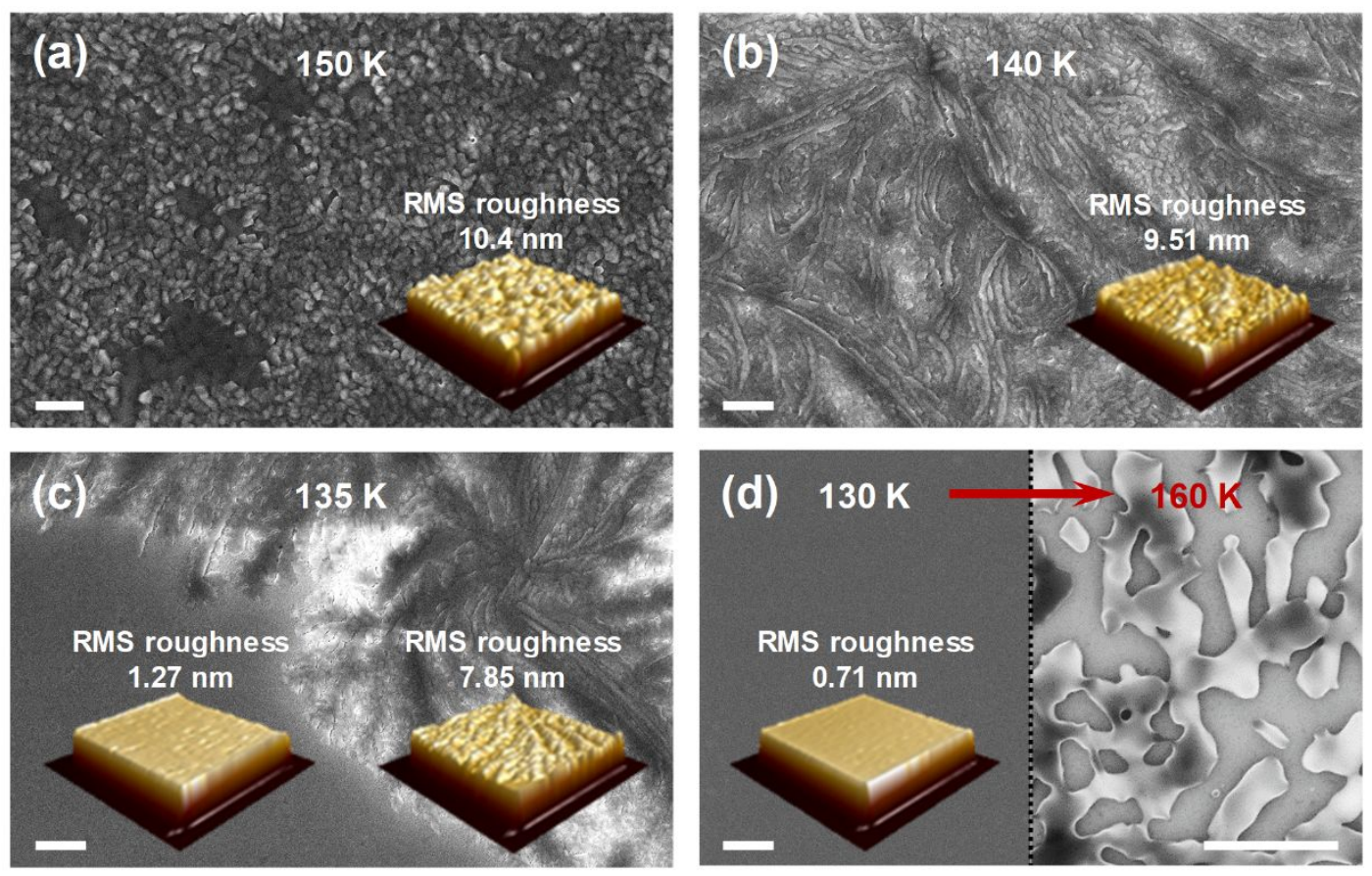

Figure 4. (a-d) In situ cryogenic SEM images (before patterning) of solid anisole at different vapor deposition temperatures. Insets are room-temperature AFM images of patterned $4 \times 4 \mu \mathrm{m}^{2}$ squares $\left(5 \mathrm{keV}, 8 \mathrm{mC} / \mathrm{cm}^{2}\right)$. The root-mean-square (RMS) roughness values were calculated from the AFM images within a $3 \mu \mathrm{m}$ by $3 \mu \mathrm{m}$ area. An island film was observed when annealed to $160 \mathrm{~K}$. All scale bars are $1 \mu \mathrm{m}$.

In order to investigate the stability of amorphous anisole, we performed patterning with different time delays in Fig. 5. A $5 \times 5$ square array was designed in the pattern layout, where $4 \times 4 \mu \mathrm{m}^{2}$ squares were evenly arranged with a distance of $10 \mu \mathrm{m}$. The squares at central "red cross" area (see false-colored SEM image in Fig. 5a) were patterned immediately after vapor deposition at $125 \mathrm{~K}$, acting as base coordinates for the measurement of pattern drift. Then other squares were patterned in a sequential order with different time delays, which are marked in Fig. 5a. 
Figure $5 \mathrm{~b}$ presents an increasing surface roughness of patterned squares over time. Initially, a smooth surface with about $1 \mathrm{~nm}$ roughness could be achieved if patterning finished in 20 minutes. When increasing time delay, the surface of solid anisole became grained although the cyrostage temperature maintained at $125 \mathrm{~K}$. The surface roughness increased to $3 \mathrm{~nm}$ when patterning was postponed to 1 hour later. The trend continues and the surface roughness stabilized at around $8 \mathrm{~nm}$ with a time delay of 2 hours. The deterioration in quality of solid anisole was also evidenced by plan view images in Fig. 5a, suggesting that the amorphous anisole was not stable and tends to be crystallized over time. To avoid rough surfaces of patterns, patterning should be finished as soon as possible after vapor deposition.

Additionally, we noted a time-dependent pattern drift that was assumed to be induced by the aforementioned stage vibration. We characterized this drift by measuring the offset between each dark square and the nearest red square in Fig. 5a. It is obvious that the offset along y-axis was much larger than along $\mathrm{x}$-axis in our apparatus, especially after a time delay of 20 minutes. Write field alignment therefore should be conducted several times during a long-time patterning. Moreover, we could compensate for the offsets in the pattern layout according to Fig. 5c, which provides a software solution for pattern drift. From instrumentation side, a laser-interferometer controlled stage will be beneficial, which has been widely utilized in dedicated e-beam writers, such as Raith eLINE lithography system. 


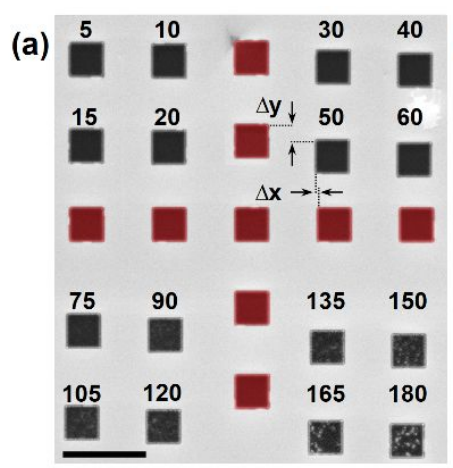

Time delay (min)

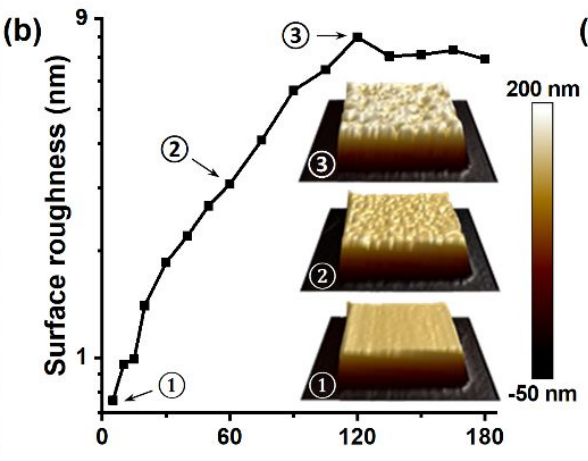

Time delay (min)

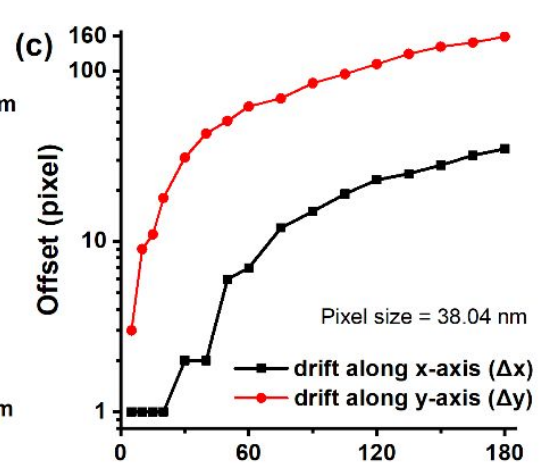

Time delay (min)

Figure 5. (a) SEM image of patterned $4 \times 4 \mathrm{~m}^{2}$ square array in a $160 \mathrm{~nm}$ thick solid anisole film with time delays. The "red cross" area was patterned immediately after vapor deposition at 125 $\mathrm{K}$. The number indicates a time delay between patterning start of each square and patterning end of the "red cross". The dose was $8 \mathrm{mC} / \mathrm{cm}^{2}$ at $5 \mathrm{keV}$ and each square patterning lasted for only 22 seconds. Scale bar is $10 \mu \mathrm{m}$. (b) Surface roughness (measured by AFM) and (c) pattern drift (measured by SEM) with varying time delays.

\subsection{Patterning on $3 \mathrm{D}$ structures}

The advantage of ice lithography is to fabricate nanostructures on irregular samples with non-flat surfaces, exemplified by patterning on AFM probes, carbon nanotubes and a single nanowire. In this paper, we demonstrate another example of 3D nanofabrication by e-beam patterning on thumb-shaped silicon micropillars with solid anisole. These 3D silicon structures (see Fig. 6a) were fabricated by multi-angled plasma etching processes with fluorine-based etching gases, ${ }^{41,42}$ where upper part and lower part of the pillars were tilted in different angles compared to the normal direction of sample surfaces. The top area of each silicon pillar is $2 \times 2 \mu \mathrm{m}^{2}$, and the height of the pillar is around $20 \mu \mathrm{m}$. Traditional EBL can hardly be performed on such kind of structures, as it is difficult to apply a uniform resist on top of the pillars by spin coating. With IL, 
amorphous solid anisole would easily cover the silicon pillars, and then a focused e-beam could write freely in the specific regions. A top view of silicon pillars with the pattern "DTU NANOLAB" and magnified titled view of characters "DTU" are shown in Figs. 6b and c, respectively. The e-beam dose was $8 \mathrm{mC} / \mathrm{cm}^{2}$ at $5 \mathrm{keV}$.

(a)

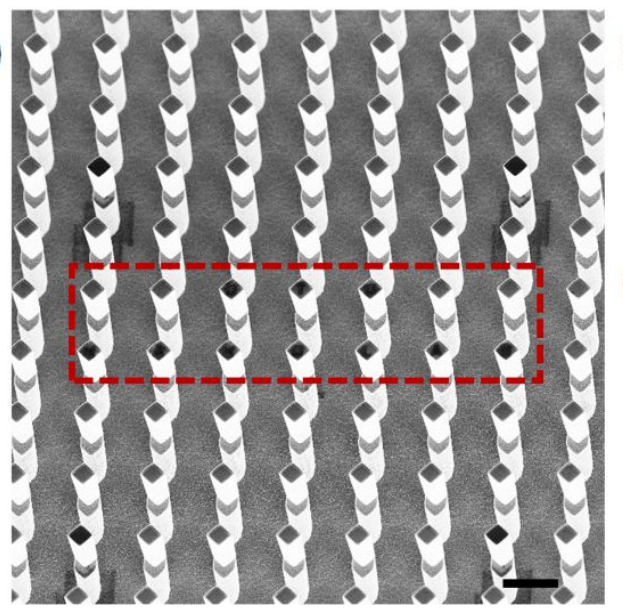

(b)

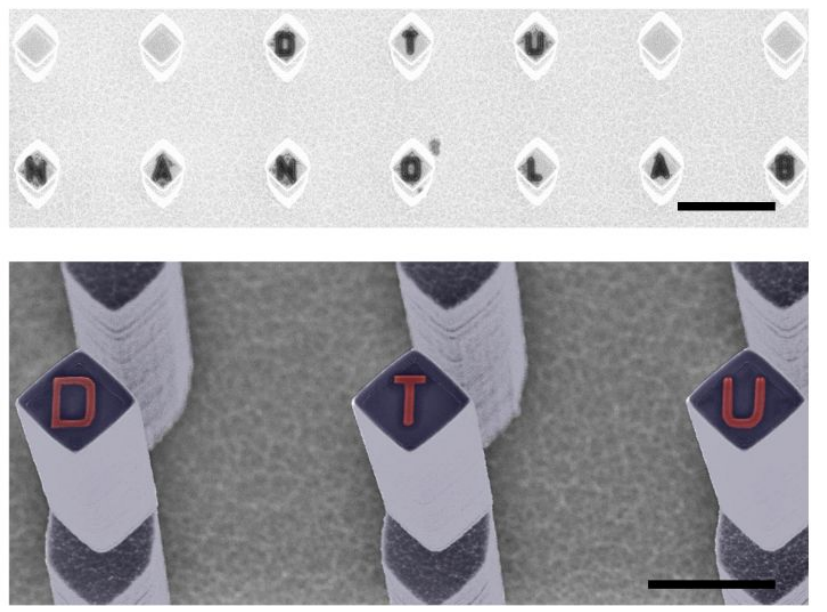

Figure 6. (a) SEM image $\left(30^{\circ}\right.$ tilt $)$ of thumb-shaped silicon micropillars. A $100 \mathrm{~nm}$ thick solid anisole layer was deposited on the top of micropillars and patterns were formed within the red rectangle area. (b) Magnified top view of the exposed pattern "DTU NANOLAB". Scale bars are $10 \mu \mathrm{m}$. (c) False-colored SEM image of patterns. Scale bar is $5 \mu \mathrm{m}$.

\section{CONCLUSIONS}

As a stimulating e-beam-based lithography technique, ice lithography enables a streamlined fabrication process and greatly extends the ability of EBL to fabricate $3 \mathrm{D}$ structures. In this paper, we have systematically investigated e-beam patterning of solid anisole and assessed its performance as an e-beam resist in IL. Our experimental results show that solid anisole holds a very low contrast of $\sim 1$ in the primary beam energy range $5-20 \mathrm{keV}$, which is quite favorable for gray-scale lithography. Severe instrumental shortcomings, both in terms of optics and 
instabilities, limit the pattern resolution (line width) of $60 \mathrm{~nm}$ at $20 \mathrm{keV}$ primary beam energy; finer lines are predictable in a more advanced system, such as recently reported linewidth of 4.5 $\mathrm{nm}$ on frozen octane in a transmission electron microscope. ${ }^{35}$ The temperature is shown to be critical for the formation of solid anisole. At $130 \mathrm{~K}$ or below, amorphous solid can be vapor deposited. Patterns with surface roughness of $\sim 0.7 \mathrm{~nm}$ are created in amorphous anisole, which is an order of magnitude smaller than in crystalline anisole. However, amorphous solid anisole cannot persist for a long time in vacuum, thus patterning should be finished as soon as possible after deposition, and recommended patterning duration is less than 1 hour, which may be prolonged under a lower cooling temperature. Pattern drift also appears during a long-time exposure, which can be compensated in pattern layout according to the time-dependent offset. Further reductions in pattern drift should be achievable once advanced hardware is employed. Currently, we have started to develop a new IL instrument at DTU Nanolab based on Raith eLINE lithography system.

\title{
AUTHOR INFORMATION \\ Corresponding Author \\ *E-mail: dizhao@dtu.dk (D.Z.), cenmb@dtu.dk (M.B.)
}

\author{
Author Contributions \\ D.Z. performed IL experiments, analyzed data and prepared figures. B.C. fabricated silicon \\ micropillars and contributed to the interpretation of the data. M.B. supervised the project. D.Z. \\ drafted the manuscript, with contributions from all other authors.
}




\section{Funding Sources}

The research presented here is supported by the DTU Nanolab and funded by the European Union's Horizon 2020 research and innovation program under the Marie Skłodowska-Curie grant agreement No. 713683.

\section{Notes}

The authors declare no competing financial interest.

\section{ACKNOWLEDGMENT}

The authors thank Nuria del Castillo Iniesta and Anna Elsukova for participating in early IL experiments.

\section{REFERENCES}

(1) Hagen, C. W. The Future of Focused Electron Beam-Induced Processing. Appl. Phys. A 2014, 117 (4), 1599-1605. https://doi.org/10.1007/s00339-014-8847-8.

(2) Krasheninnikov, A. V.; Banhart, F. Engineering of Nanostructured Carbon Materials with Electron or Ion Beams. Nature Materials. 2007. https://doi.org/10.1038/nmat1996.

(3) Utke, I.; Hoffmann, P.; Melngailis, J. Gas-Assisted Focused Electron Beam and Ion Beam Processing and Fabrication. J. Vac. Sci. Technol. B Microelectron. Nanom. Struct. 2008. https://doi.org/10.1116/1.2955728.

(4) Martin, A. A.; Toth, M. Cryogenic Electron Beam Induced Chemical Etching. ACS Appl. Mater. Interfaces 2014. https://doi.org/10.1021/am506163w.

(5) Palazon, F.; Prato, M.; Manna, L. Writing on Nanocrystals: Patterning Colloidal Inorganic Nanocrystal Films through Irradiation-Induced Chemical Transformations of Surface Ligands. Journal of the American Chemical Society. 2017. https://doi.org/10.1021/jacs.7b05888.

(6) Bishop, J.; Fronzi, M.; Elbadawi, C.; Nikam, V.; Pritchard, J.; Fröch, J. E.; Duong, N. M. H.; Ford, M. J.; Aharonovich, I.; Lobo, C. J.; Toth, M. Deterministic Nanopatterning of Diamond Using Electron Beams. ACS Nano 2018, 12 (3), 2873-2882. https://doi.org/10.1021/acsnano.8b00354.

(7) Fisher, J. S.; Kottke, P. A.; Kim, S.; Fedorov, A. G. Rapid Electron Beam Writing of Topologically Complex 3D Nanostructures Using Liquid Phase Precursor. Nano Lett. 2015. https://doi.org/10.1021/acs.nanolett.5b04225.

(8) Fowlkes, J. D.; Winkler, R.; Lewis, B. B.; Stanford, M. G.; Plank, H.; Rack, P. D. Simulation-Guided 3D Nanomanufacturing via Focused Electron Beam Induced Deposition. ACS Nano 2016. https://doi.org/10.1021/acsnano.6b02108. 
(9) Winkler, R.; Schmidt, F.-P.; Haselmann, U.; Fowlkes, J. D.; Lewis, B. B.; Kothleitner, G.; Rack, P. D.; Plank, H. Direct-Write 3D Nanoprinting of Plasmonic Structures. ACS Appl. Mater. Interfaces 2017, 9 (9), 8233-8240. https://doi.org/10.1021/acsami.6b13062.

(10) Duan, H.; Xie, E.; Han, L.; Xu, Z. Turning PMMA Nanofibers into Graphene Nanoribbons by in Situ Electron Beam Irradiation. Adv. Mater. 2008. https://doi.org/10.1002/adma.200702149.

(11) Xu, S.; Tian, M.; Wang, J.; Xu, J.; Redwing, J. M.; Chan, M. H. W. Nanometer-Scale Modification and Welding of Silicon and Metallic Nanowires with a High-Intensity Electron Beam. Small 2005. https://doi.org/10.1002/smll.200500240.

(12) Pennelli, G.; Totaro, M.; Piotto, M. Selective Doping of Silicon Nanowires by Means of Electron Beam Stimulated Oxide Etching. Nano Letters. 2012. https://doi.org/10.1021/nl2045183.

(13) Chen, Y. Nanofabrication by Electron Beam Lithography and Its Applications: A Review. Microelectron. Eng. 2015, 135, 57-72. https://doi.org/10.1016/j.mee.2015.02.042.

(14) Yoon, G.; Kim, I.; So, S.; Mun, J.; Kim, M.; Rho, J. Fabrication of Three-Dimensional Suspended, Interlayered and Hierarchical Nanostructures by Accuracy-Improved Electron Beam Lithography Overlay. Sci. Rep. 2017, 7 (1), 6668. https://doi.org/10.1038/s41598017-06833-5.

(15) Mendes, P. M.; Jacke, S.; Critchley, K.; Plaza, J.; Chen, Y.; Nikitin, K.; Palmer, R. E.; Preece, J. A.; Evans, S. D.; Fitzmaurice, D. Gold Nanoparticle Patterning of Silicon Wafers Using Chemical E-Beam Lithography. Langmuir 2004. https://doi.org/10.1021/la049803g.

(16) Joo, J.; Chow, B. Y.; Jacobson, J. M. Nanoscale Patterning on Insulating Substrates by Critical Energy Electron Beam Lithography. Nano Lett. 2006. https://doi.org/10.1021/n1061211q.

(17) Manfrinato, V. R.; Zhang, L.; Su, D.; Duan, H.; Hobbs, R. G.; Stach, E. A.; Berggren, K. K. Resolution Limits of Electron-Beam Lithography toward the Atomic Scale. Nano Lett. 2013, 13 (4), 1555-1558. https://doi.org/10.1021/nl304715p.

(18) Huang, J.; Lee, M.; Lucero, A.; Cheng, L.; Kim, J. Area-Selective ALD of TiO2 Nanolines with Electron-Beam Lithography. J. Phys. Chem. C 2014. https://doi.org/10.1021/jp5037662.

(19) Arnob, M. M. P.; Zhao, F.; Li, J.; Shih, W. C. EBL-Based Fabrication and Different Modeling Approaches for Nanoporous Gold Nanodisks. ACS Photonics 2017. https://doi.org/10.1021/acsphotonics.7b00239.

(20) Manfrinato, V. R.; Stein, A.; Zhang, L.; Nam, C.-Y.; Yager, K. G.; Stach, E. A.; Black, C. T. Aberration-Corrected Electron Beam Lithography at the One Nanometer Length Scale. Nano Lett. 2017, 17 (8), 4562-4567. https://doi.org/10.1021/acs.nanolett.7b00514.

(21) Zhang, J.; Con, C.; Cui, B. Electron Beam Lithography on Irregular Surfaces Using an Evaporated Resist. ACS Nano 2014, 8 (4), 3483-3489. https://doi.org/10.1021/nn4064659.

(22) Con, C.; Zhang, J.; Cui, B. Nanofabrication of High Aspect Ratio Structures Using an Evaporated Resist Containing Metal. Nanotechnology 2014, 25 (17), 175301. https://doi.org/10.1088/0957-4484/25/17/175301.

(23) Yamazaki, K.; Yamaguchi, H. Electron Beam Lithography on Vertical Side Faces of Micrometer-Order Si Block. J. Vac. Sci. Technol. B, Nanotechnol. Microelectron. Mater. Process. Meas. Phenom. 2012, 30 (4), 041601. https://doi.org/10.1116/1.4719561.

(24) Yamazaki, K.; Yamaguchi, H. Resist Coating on Vertical Side Faces Using Conventional 
Spin Coating for Creating Three-Dimensional Nanostructures in Semiconductors. Appl. Phys. Express 2010, 3 (10), 106501. https://doi.org/10.1143/APEX.3.106501.

(25) Zhou, H.; Chong, B. K.; Stopford, P.; Mills, G.; Midha, A.; Donaldson, L.; Weaver, J. M. R. Lithographically Defined Nano and Micro Sensors Using `float Coating' of Resist and Electron Beam Lithography. J. Vac. Sci. Technol. B Microelectron. Nanom. Struct. 2000, 18 (6), 3594-3599. https://doi.org/10.1116/1.1321271.

(26) Cai, H.; Meng, Q.; Ding, H.; Zhang, K.; Lin, Y.; Ren, W.; Yu, X.; Wu, Y.; Zhang, G.; Li, M.; Pan, N; Qi, Z; Tian, Y; Luo, Y; Wang, X. Utilization of Resist Stencil Lithography for Multidimensional Fabrication on a Curved Surface. ACS Nano 2018, 12 (9), 9626-9632. https://doi.org/10.1021/acsnano.8b06534.

(27) Kim, S.; Marelli, B.; Brenckle, M. A.; Mitropoulos, A. N.; Gil, E. S.; Tsioris, K.; Tao, H.; Kaplan, D. L.; Omenetto, F. G. All-Water-Based Electron-Beam Lithography Using Silk as a Resist. Nat. Nanotechnol. 2014, 9 (4), 306-310. https://doi.org/10.1038/nnano.2014.47.

(28) Jiang, B.; Yang, J.; Li, C.; Zhang, L.; Zhang, X.; Yang, P. Water-Based Photo- and Electron-Beam Lithography Using Egg White as a Resist. Adv. Mater. Interfaces 2017, 4 (7), 1601223. https://doi.org/10.1002/admi.201601223.

(29) King, G. M.; Schürmann, G.; Branton, D.; Golovchenko, J. A. Nanometer Patterning with Ice. Nano Lett. 2005, 5 (6), 1157-1160. https://doi.org/10.1021/n1050405n.

(30) Zhao, D.; Han, A.; Qiu, M. Ice Lithography for 3D Nanofabrication. Science Bulletin. Elsevier B.V. June 30, 2019, pp 865-871. https://doi.org/10.1016/j.scib.2019.06.001.

(31) Han, A.; Kuan, A.; Golovchenko, J.; Branton, D. Nanopatterning on Nonplanar and Fragile Substrates with Ice Resists. Nano Lett. 2012, 12 (2), 1018-1021. https://doi.org/10.1021/nl204198w.

(32) Han, A.; Vlassarev, D.; Wang, J.; Golovchenko, J. A.; Branton, D. Ice Lithography for Nanodevices. Nano Lett. 2010, 10 (12), 5056-5059. https://doi.org/10.1021/nl1032815.

(33) Hong, Y.; Zhao, D.; Liu, D.; Ma, B.; Yao, G.; Li, Q.; Han, A.; Qiu, M. Three-Dimensional in Situ Electron-Beam Lithography Using Water Ice. Nano Lett. 2018, 18 (8), 5036-5041. https://doi.org/10.1021/acs.nanolett.8b01857.

(34) Tiddi, W.; Elsukova, A.; Le, H. T.; Liu, P.; Beleggia, M.; Han, A. Organic Ice Resists. Nano Lett. 2017, 17 (12), 7886-7891. https://doi.org/10.1021/acs.nanolett.7b04190.

(35) Elsukova, A.; Han, A.; Zhao, D.; Beleggia, M. Effect of Molecular Weight on the Feature Size in Organic Ice Resists. Nano Lett. 2018, 18 (12), 7576-7582. https://doi.org/10.1021/acs.nanolett.8b03130.

(36) Tiddi, W.; Elsukova, A.; Beleggia, M.; Han, A. Organic Ice Resists for 3D Electron-Beam Processing: Instrumentation and Operation. Microelectron. Eng. 2018, 192, 38-43. https://doi.org/10.1016/j.mee.2018.01.021.

(37) Waits, C. M.; Morgan, B.; Kastantin, M.; Ghodssi, R. Microfabrication of 3D Silicon MEMS Structures Using Gray-Scale Lithography and Deep Reactive Ion Etching. Sensors Actuators, A Phys. 2005, 119 (1), 245-253. https://doi.org/10.1016/S09244247(04)00193-1.

(38) Fairley, K. C.; Sharps, M. C.; Mitchson, G.; Ditto, J.; Johnson, D. W.; Johnson, D. C. Sub-30 KeV Patterning of HafSOx Resist: Effects of Voltage on Resolution, Contrast, and Sensitivity. J. Vac. Sci. Technol. B, Nanotechnol. Microelectron. Mater. Process. Meas. Phenom. 2016, 34 (4), 041607. https://doi.org/10.1116/1.4954394.

(39) Kudryashov, V.; Yuan, X.-C.; Cheong, W.-C.; Radhakrishnan, K. Grey Scale Structures 
Formation in SU-8 with e-Beam and UV. Microelectron. Eng. 2003, 67-68, 306-311. https://doi.org/10.1016/S0167-9317(03)00083-2.

(40) Millot, M.; Coppari, F.; Rygg, J. R.; Correa Barrios, A.; Hamel, S.; Swift, D. C.; Eggert, J. H. Nanosecond X-Ray Diffraction of Shock-Compressed Superionic Water Ice. Nature. 2019. https://doi.org/10.1038/s41586-019-1114-6.

(41) Chang, B.; Leussink, P.; Jensen, F.; Hübner, J.; Jansen, H. DREM: Infinite Etch Selectivity and Optimized Scallop Size Distribution with Conventional Photoresists in an Adapted Multiplexed Bosch DRIE Process. Microelectron. Eng. 2018, 191, 77-83. https://doi.org/10.1016/j.mee.2018.01.034.

(42) Chang, B. Oblique Angled Plasma Etching for 3D Silicon Structures with Wiggling Geometries. Nanotechnology 2019, 31 (8), 85301. 


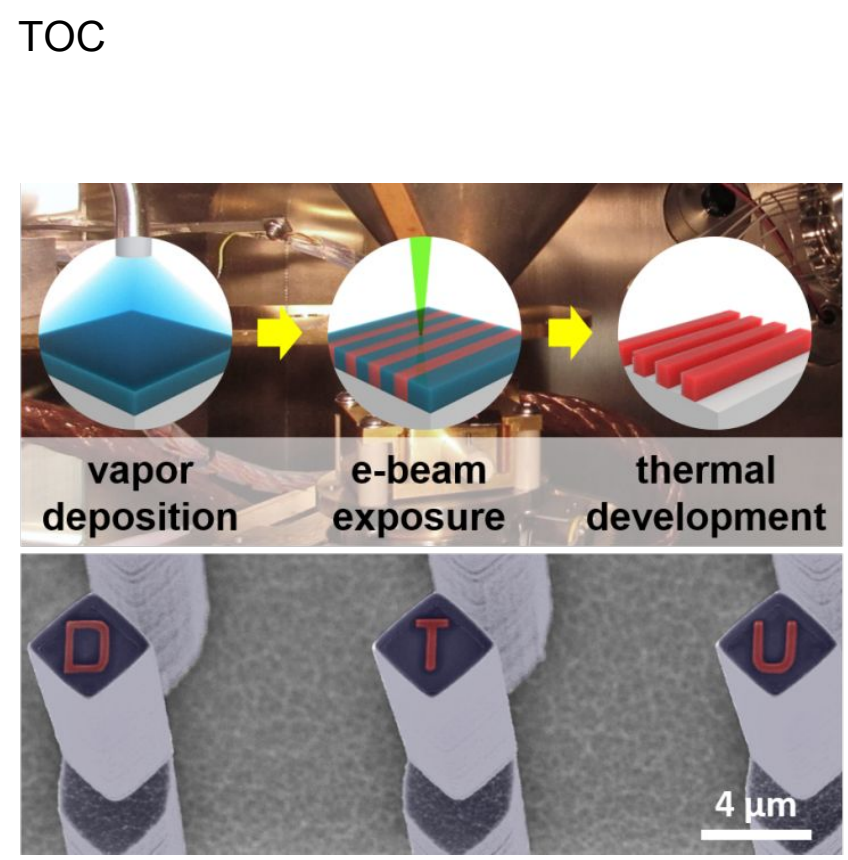

